\title{
Lambert W-function simplified expressions for photovoltaic current-voltage modelling
}

\author{
Elena Roibás-Millán \\ Instituto de Microgravedad "Ignacio Da \\ Riva” (IDR/UPM) \\ Escuela Técnica Superior de Ingeniería \\ Aeronáutica y del Espacio (ETSIAE), \\ Universidad Politécnica de Madrid \\ Madrid, Spain \\ elena.roibas@upm.es
}

Rocío Jado-Puente

Instituto de Microgravedad "Ignacio Da Riva" (IDR/UPM)

Escuela Técnica Superior de Ingeniería Aeronáutica y del Espacio (ETSIAE),

Universidad Politécnica de Madrid

Madrid, Spain

rocio.jado.puente@alumnos.upm.es

José Miguel Álvarez

Instituto de Microgravedad "Ignacio Da Riva" (IDR/UPM)

Escuela Técnica Superior de Ingeniería Aeronáutica y del Espacio (ETSIAE),

Universidad Politécnica de Madrid Madrid, Spain

im.alvarez@upm.es

\author{
Juan L. Cubero-Estalrrich \\ Instituto de Microgravedad "Ignacio Da \\ Riva” (IDR/UPM) \\ Escuela Técnica Superior de Ingeniería \\ Aeronáutica y del Espacio (ETSIAE), \\ Universidad Politécnica de Madrid \\ Madrid, Spain \\ j1.cubero@alumnos.upm.es
}

Marlon Sanabria-Pinzón

Instituto de Microgravedad "Ignacio Da Riva” (IDR/UPM)

Escuela Técnica Superior de Ingeniería Aeronáutica y del Espacio (ETSIAE),

Universidad Politécnica de Madrid

Madrid, Spain

ms.sanabria@alumnos.upm.es

Javier Cubas

Instituto de Microgravedad "Ignacio Da Riva" (IDR/UPM)

Escuela Técnica Superior de Ingeniería Aeronáutica y del Espacio (ETSIAE),

Universidad Politécnica de Madrid Madrid, Spain

i.cubas@upm.es

\author{
Alejandro Gonzalez-Estrada \\ Instituto de Microgravedad "Ignacio Da \\ Riva” (IDR/UPM) \\ Escuela Técnica Superior de Ingeniería \\ Aeronáutica y del Espacio (ETSIAE), \\ Universidad Politécnica de Madrid \\ Madrid, Spain \\ alejandro.gonzalez.estrada@alumnos.upm.es
}

\section{Daniel Alfonso-Corcuera \\ Instituto de Microgravedad "Ignacio Da Riva" (IDR/UPM) \\ Escuela Técnica Superior de Ingeniería Aeronáutica y del Espacio (ETSIAE), \\ Universidad Politécnica de Madrid Madrid, Spain \\ daniel.alfonso.corcuera@alumnos.upm.es}

Santiago Pindado

Instituto de Microgravedad "Ignacio Da Riva" (IDR/UPM)

Escuela Técnica Superior de Ingeniería Aeronáutica y del Espacio (ETSIAE),

Universidad Politécnica de Madrid Madrid, Spain

santiago.pindado@upm.es

\begin{abstract}
In this paper, the first work carried out at the IDR/UPM Institute within the frame of the educational innovation project PIRAMIDE is presented. This work is related to photovoltaic behavior modeling simplification. The aim is to derive simplified and easy-to-work-with equations for the Lambert W-function. This mathematical function represents a quite useful tool when modeling solar cells/panels performance (that is, the current-voltage curve) by analytical approaches. However, the Lambert $\mathrm{W}$-function has a complex solving process which might represent an unaffordable mathematical challenge for a great number of professionals/technicians from the photovoltaic industrial sector. Simple approximations for the Lambert $\mathrm{W}$-function on both of its branches (positive and negative), are proposed in this work. The results of the present work show a simple but accurate way of photovoltaic systems modeling, even when working with the implicit equation of the 1-Diode/2-Resistor equivalent circuit model (whose solution is given in the present work by an explicit equation).
\end{abstract}

Keywords-Lambert W-function, solar cell, solar panel, photovoltaic device, performance, I-V curve, 1-Diode/2-Resistor model

\section{INTRODUCTION}

Within the last years and thanks to the work carried out in space systems projects (see Fig.1), a strong research line on solar cells/panels modeling has been established at Instituto Universitario de Microgravedad "Ignacio Da Riva" (IDR/UPM) from Universidad Politécnica de Madrid (UPM) [1]-[10]. The development of this research line was motivated by the need of simple analytical procedures to generate quick solutions to accelerate early design of space systems.
Two kind of different models have been developed and used at IDR/UPM:

- $\quad$ Based on the 1-Diode/2-Resistor equivalent circuit model (see Fig.2), which leads to an implicit equation.

- Explicit models, which are defined by means of explicit mathematical expressions.

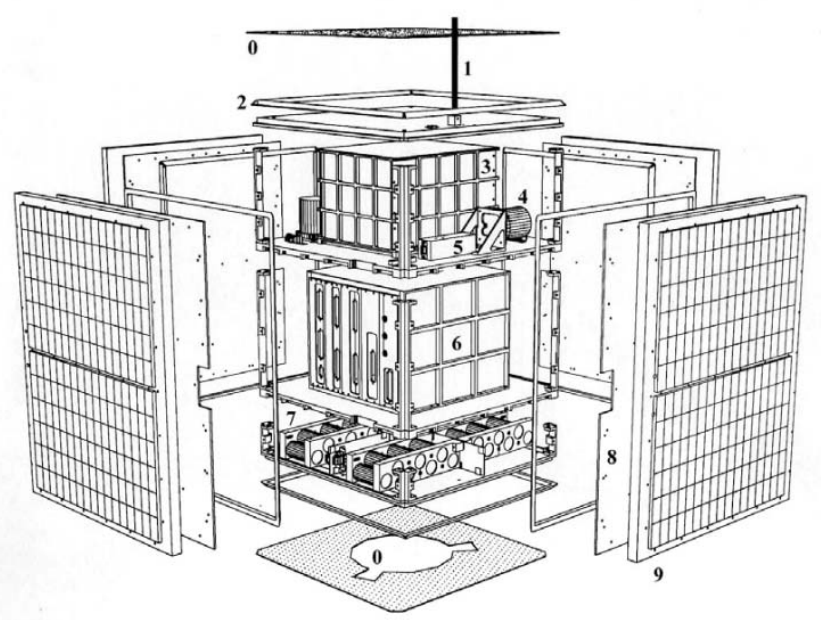

Fig. 1 Sketch of the UPMSat-1 satellite. Developed by IDR/UPM researchers, it was launched in 1995 , this project being the $10^{\text {th }}$ universitydeveloped space mission in History [11]. More information on the space engineering projects developed at the IDR/UPM Institute can be found in

[12]. 
The work included in this paper has been carried out within the frame of the educational innovation project PIRAMIDE. This project involves Professors and students from UPM, its aim being to promote research techniques and procedures, in an attempt to boost the academic results of Bachelor and Master students from the aerospace engineering degrees at UPM university.

The aim of the present paper is firstly to slightly describe the models developed and used at the IDR/UPM Institute to analyze the solar cells/panels, and then point out how these models drive the user to an expression that includes the Lambert W-function. A description of the Lambert Wfunction is also included. After that, the intervals of the variable where this function needs to be evaluated are analyzed by using solar cells/panels data obtained from the available literature. Finally, simplified expressions for the Lambert $\mathrm{W}$-function are proposed.

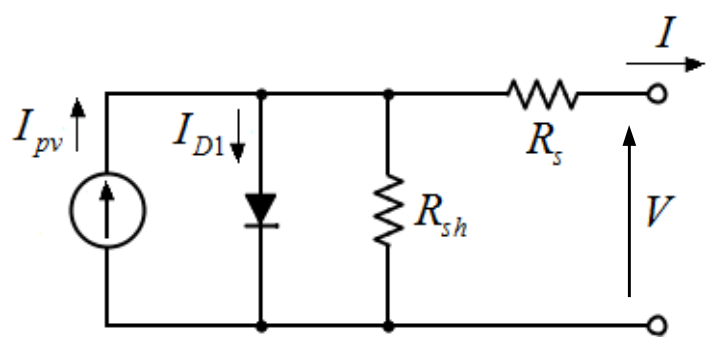

Fig. 2 Solar cell/panel 1-Diode/2-Resistor equivalent circuit.

The present paper is organized as follows. In Section II, the solar cell/panel models are described, together with the Lambert W-function. In Section III, results based on the data collected from the available literature are shown, together with the expressions proposed and their accuracy. Finally, conclusions are summarized in Section IV.

\section{SOLAR CELL/PANEL MODELS}

\section{A. The 1-diode/2-resistor equivalent circuit model}

The equation that relates the output current, $I$, to the output voltage, $V$, in the 1-Diode/2-Resistor equivalent circuit model (see Fig. 2) is the following [1]:

$$
I=I_{p v}-I_{0}\left[\exp \left(\frac{V+I R_{s}}{n a V_{T}}\right)-1\right]-\frac{V+I R_{s}}{R_{s h}}
$$

in which the first term is the photocurrent, the second one is the current through the diode, and the third term represents the current through the shunt resistor. $V_{T}$ is the thermal voltage $\left(V_{T}=\kappa T / q ; \kappa\right.$ being the Boltzmann constant, $T$ the temperature, and $q$ the electron charge), $a$ is the ideality factor of the diode, and finally $n$ is the number of seriesconnected cells within the panel. Working with the above equation is not a simple task, as the parameters involved in the equation $\left(I_{p v}, I_{0}, a, R_{s}\right.$, and $\left.R_{s h}\right)$ should be calculated, in relation to both the solar irradiance, $G$, on the cell/panel and its temperature, $T$, before using this model. Besides, equation (1) is an implicit mathematical expression. Therefore, for a given value of the output voltage, $V$, the calculation of the corresponding output current, $I$, is not immediate, being an iteration process necessary. Nevertheless, different methodologies have been developed to work with this equation depending on the available information [13]-[19].

If the characteristic points of the $I-V$ curve (see Fig. 3):
- $\quad$ short circuit current, $I_{s c}$,

- $\quad$ open circuit voltage, $V_{o c}$

- $\quad$ and current and voltage at maximum power point, $I_{m p}$ and $\left.V_{m p}\right)$,

are known for certain values of the sun irradiance, $G$, and the temperature, $T$, it is possible to calculate the four of the parameters of the model in relation to the fifth one, which is the ideality factor, $a[1]$, [3]:

$$
\begin{gathered}
I_{p v}=\frac{R_{s h}+R_{s}}{R_{s h}} I_{s c}, \\
I_{0}=\frac{\left(R_{s h}+R_{s}\right) I_{s c}-V_{o c}}{R_{s h} \exp \left(\frac{V_{o c}}{n a V_{T}}\right)} \\
\frac{n a V_{T} V_{m p}\left(2 I_{m p}-I_{s c}\right)}{\left(V_{m p} I_{s c}+V_{o c}\left(I_{m p}-I_{s c}\right)\right)\left(V_{m p}-I_{m p} R_{s}\right)-n a V_{T}\left(V_{m p} I_{s c}-V_{o c} I_{m p}\right)}, \\
=\exp \left(\frac{V_{m p}+I_{m p} R_{s}-V_{o c}}{n a V_{T}}\right) \\
R_{s h}=\frac{\left(V_{m p}-I_{m p} R_{s}\right)\left(V_{m p}-R_{s}\left(I_{s c}-I_{m p}\right)-n a V_{T}\right)}{\left(V_{m p}-I_{m p} R_{s}\right)\left(I_{s c}-I_{m p}\right)-n a V_{T} I_{m p}} .
\end{gathered}
$$

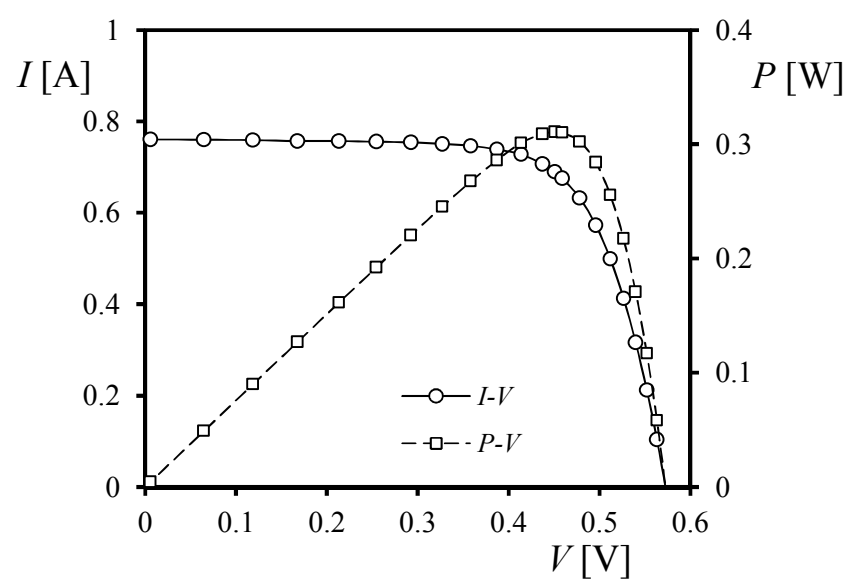

Fig. $3 I-V$ (current-voltage) and $P-V$ (power-voltage) curves of a Si solar cell.

Therefore, once the ideality factor $a$, has been estimated (according to [20], [21] its value is within the bracket [1, $1.5]$ ), it is possible to obtain sequentially $R_{s}$ (from equation (4)), $R_{s h}$ (from equation (5)), $I_{0}$ (from equation (3)), and $I_{p v}$ (from equation (2)). Finally, the output current, $I$, can be defined for each value of the output voltage, $V$, by means of an iterative process, or the following equation [23]:

$$
\begin{aligned}
& I=\frac{R_{s h}\left(I_{p v}+I_{0}\right)-V}{R_{s h}+R_{s}}- \\
& \frac{n a V_{T}}{R_{s}} W_{0}\left(\frac{R_{s h} R_{s} I_{0}}{n a V_{T}\left(R_{s h}+R_{s}\right)} \exp \left(\frac{R_{s h} R_{s}\left(I_{p v}+I_{0}\right)+R_{s h} V}{n a V_{T}\left(R_{s h}+R_{s}\right)}\right)\right)^{,}
\end{aligned}
$$

where $W_{0}$ is the positive branch of the Lambert $\mathrm{W}$-function. 
Alternatively, and as solving equation (4) to obtain the value of $R_{s}$ requires an iterative process, this parameter can be obtained from [2]:

$$
R_{s}=A\left(W_{-1}(B \exp (C))-(D+C)\right),
$$

where $W_{-1}$ is the negative branch of the Lambert $\mathrm{W}$-function and:

$$
\begin{gathered}
A=\frac{n a V_{T}}{I_{m p}}, \\
B=-\frac{V_{m p}\left(2 I_{m p}-I_{s c}\right)}{V_{m p} I_{s c}+V_{o c}\left(I_{m p}-I_{s c}\right)}, \\
C=-\frac{2 V_{m p}-V_{o c}}{n a V_{T}}+\frac{V_{m p} I_{s c}-V_{o c} I_{m p}}{V_{m p} I_{s c}+V_{o c}\left(I_{m p}-I_{s c}\right)}, \\
D=\frac{V_{m p}-V_{o c}}{n a V_{T}} .
\end{gathered}
$$

\section{B. Explicit models based on the Lambert $W$-function}

There are several explicit models to analyze the currentvoltage performance of a solar cell/panel [23]. Although these approximations do not preserve any physical aspect of the photovoltaic conversion process, they are interesting and accurate enough to generate new works from time to time [24]. Among the explicit models, the ones that reach a solution based on the Lambert $\mathrm{W}$-function are:

- El-Tayyan's model:

$$
I=I_{s c}-C_{1} \exp \left(-\frac{V_{o c}}{C_{2}}\right)\left(\exp \left(\frac{V}{C_{2}}\right)-1\right),
$$

where:

$$
C_{1}=\frac{I_{s c}}{1-\exp \left(-\frac{V_{o c}}{C_{2}}\right)},
$$

and, if $V_{o c} / C_{2}>>1$ :

$$
C_{2}=\frac{V_{m p}-V_{o c}}{W_{-1}\left(\left(1-\frac{V_{o c}}{V_{m p}}\right)\left(\frac{I_{m p}}{I_{s c}}\right)\right)} .
$$

- Karmalkar \& Haneefa’s model:

$$
\frac{I}{I_{s c}}=1-(1-\gamma)\left(\frac{V}{V_{o c}}\right)-\gamma\left(\frac{V}{V_{o c}}\right)^{m} .
$$

where:

$$
\begin{gathered}
\gamma=\frac{2\left(\frac{I_{m p}}{I_{s c}}\right)-1}{(m-1)\left(\frac{V_{m p}}{V_{o c}}\right)^{m}}, \\
m=\frac{W_{-1}\left(-\left(\frac{V_{o c}}{V_{m p}}\right)^{\frac{1}{K}}\left(\frac{1}{K}\right) \ln \left(\frac{V_{m p}}{V_{o c}}\right)\right)}{\ln \left(\frac{V_{m p}}{V_{o c}}\right)}+\frac{1}{K}+1,
\end{gathered}
$$

with:

$$
K=\frac{1-\left(\frac{I_{m p}}{I_{s c}}\right)-\left(\frac{V_{m p}}{V_{o c}}\right)}{2\left(\frac{I_{m p}}{I_{s c}}\right)-1},
$$

- Das' model:

$$
\frac{I}{I_{s c}}=\frac{1-\left(\frac{V}{V_{o c}}\right)^{k}}{1+h\left(\frac{V}{V_{o c}}\right)},
$$

where:

$$
\begin{gathered}
k=\frac{W_{-1}\left(\left(\frac{I_{m p}}{I_{s c}}\right) \ln \left(\frac{V_{m p}}{V_{o c}}\right)\right)}{\ln \left(\frac{V_{m p}}{V_{o c}}\right)}, \\
h=\left(\frac{V_{o c}}{V_{m p}}\right)\left(\frac{I_{s c}}{I_{m p}}-\frac{1}{k}-1\right) .
\end{gathered}
$$

\section{The Lambert $W$-function}

The Lambert W-function, $W(z)$, is defined as:

$$
z=W(z) \exp (W(z))
$$

where $z$ is a complex number. For a real variable $x$, the Lambert function is defined within the bracket $[-1 / \mathrm{e}, \infty]$, having a double value within the bracket $[-1 / \mathrm{e}, 0]$. Two different branches are defined for this function: $W_{0}(x)$, for $W(x) \geq-1$, and $W_{-1}(x)$, for $W(x) \leq-1$. Additionally, the branch $W_{0}(x)$ is divided into two sections that can be better approached separately: $W_{0}^{-}(x)$, for $W_{0}(x) \leq 0$, and $W_{0}^{+}(x)$, for $W_{0}(x) \geq 0$, see Fig. 4

This is a quite complex function that needs some computational aid to be solved. Although easier approximations to this function can be found in the literature, such as the one proposed by Barry et al. [25], they are still too complex to be considered "direct" equations. 


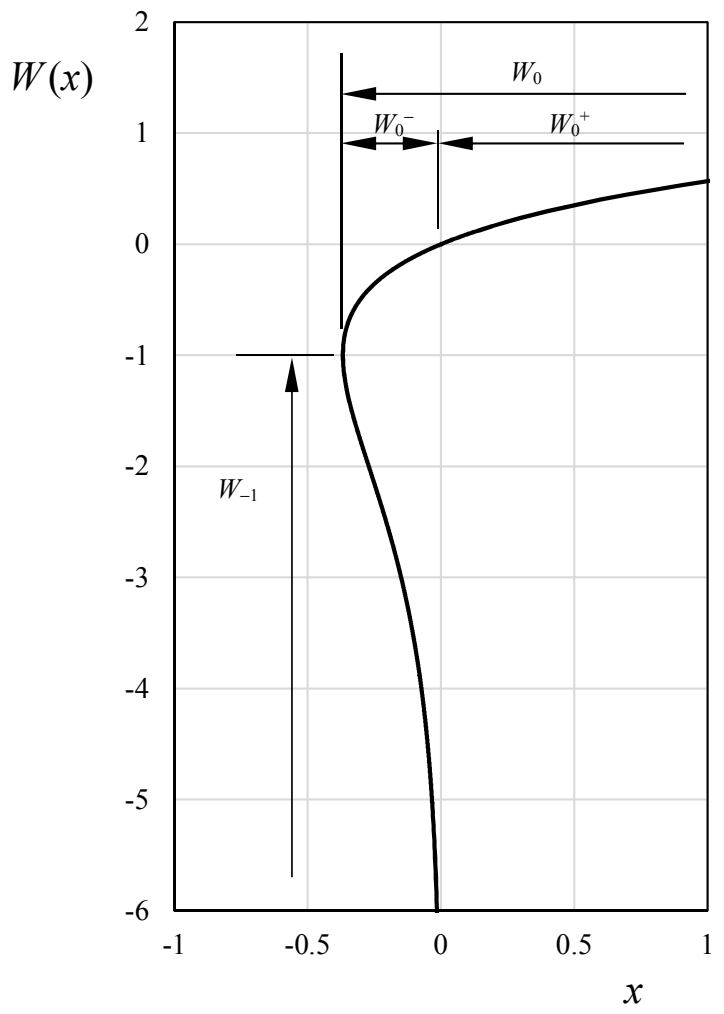

Fig. 4 Lambert W-function. The different branches are indicated in the graph.

\section{RESULTS}

A thorough review of the available literature was carried out, in order to obtain sufficient large data to derive accurate mathematical expressions for the Lambert W-function within the appropriate $x$ variable range (where this function needs to be calculated).

The relevant data (i.e., the five parameters of the 1Diode/2-Resistors model $I_{p v}, I_{0}, a, R_{s}$, and $R_{s h}$, the number of cells series-connected, $n$, the temperature in which the $I-V$ curve is measured or calculated, $T$, and the four characteristic points, $I_{s c}, V_{o c}, I_{m p}$, and $V_{m p}$ ), from 89 different photovoltaic devices (mostly solar panels) were found.

If we go to the equation (6), that allows us to calculate the current for a variable $x$ that is written in relation to the aforementioned five parameters of the 1-Diode/2-Resistors model, the number of cells series-connected, the temperature and the output voltage, $V$ :

$$
x=f\left(I_{p v}, I_{0}, a, R_{s}, R_{s h}, n, T, V\right) .
$$

Bearing in mind that, when evaluating the performance of a photovoltaic device, two extremes of the above variable, $x$, arise at short circuit $(V=0)$ and open circuit $\left(V=V_{o c}\right)$ points, it is possible to define a characteristic interval for evaluating the Lambert $\mathrm{W}$-function in relation to equation (6). The values of the Lambert W-function $W_{0}^{+}$calculated at each point (equation (23)) with the data from each photovoltaic device found at the available literature, at $V=0$ and $V=V_{o c}$, are shown in Fig. 5. Based on these points, included in the bracket $\left[10^{-20}, 10^{-5}\right]$, the following approximation is proposed:

$$
\begin{aligned}
& W_{0}^{+}(x)=x- \\
& \exp \left(4.123 \cdot 10^{-6} \ln (x)^{2}+2 \ln (x)+1.64 \cdot 10^{-4}\right)
\end{aligned} .
$$

The above equation has been also plotted in Fig. 5. It should be added that this equation has $1.4 \%$ error for $x=0.1$, the accuracy being improved for lower values of $x$.

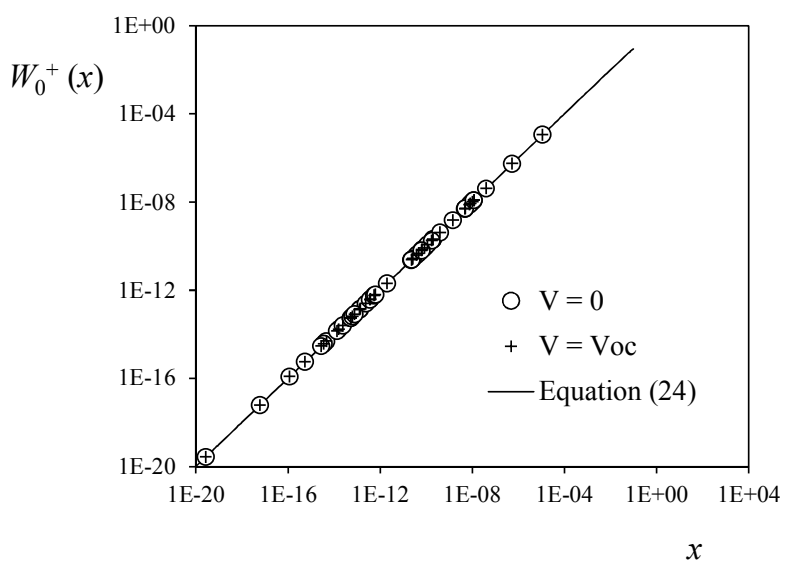

Fig. 5 Lambert W-function, $W_{0}^{+}$from equation (6) calculated at $V=0$ and $V$ $=V_{o c}$ for the cells/solar panels' data found in the available literature. The approximated equation (24) is also plotted in the graph.

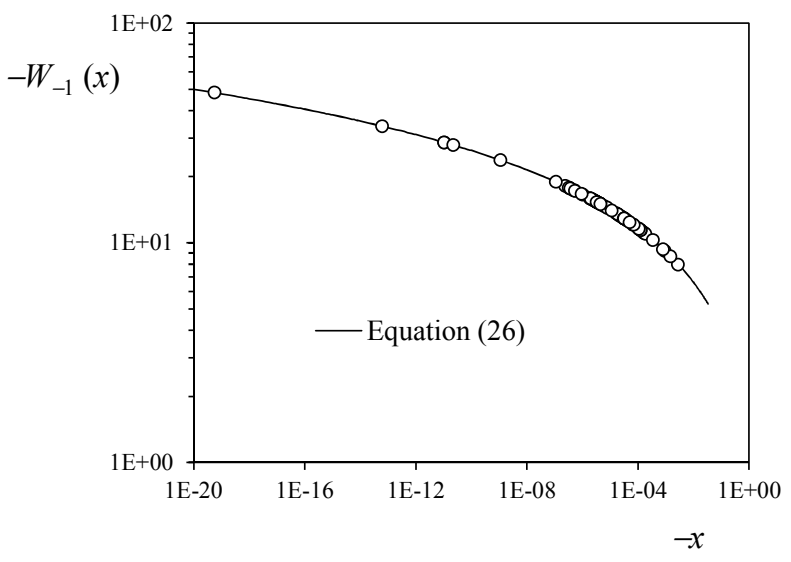

Fig. 6 Lambert W-function, $W_{-1}$ from equation (7) calculated for the cells/solar panels' data found in the available literature. The approximated equation (26) is also plotted in the graph.

The negative branch of the Lambert $\mathrm{W}$-function, $W_{-1}$, allows the user to calculate the series resistor of the 1Diode/2-Resistor model, $R_{s}$, in relation to the characteristic points, the number of cells series-connected, the ideality factor and the temperature (equation (7)). Therefore, $W_{-1}$ is required to be evaluated at:

$$
x=f\left(I_{s c}, I_{m p}, V_{o c}, V_{m p}, a, n, T\right) .
$$

In Fig. 6, the values of $W_{-1}$, calculated at the values of the above variable $x$ resulting from the solar cells and panels data found in the literature, are plotted. The bracket in which the Lambert $\mathrm{W}$-function $W_{-1}$ needs to be evaluated is $\left[10^{-20}\right.$, $\left.10^{-3}\right]$. The following simple expression is proposed for these estimations: 


$$
\begin{aligned}
& W_{-1}(x)=2.4978 \cdot 10^{-5} \ln (-x)^{3}+ \\
& 2.8111 \cdot 10^{-3} \ln (-x)^{2}+1.1299 \ln (-x)-1.4733
\end{aligned} .
$$

This equation is also plotted in Fig. 6. The maximum error in equation (26) was proven to be below $0.4 \%$ within the mentioned bracket.

With regard to the explicit models that need the Lambert W-function (equations (14), (17) and (20)), the values of this function are plotted in Fig. 7, in relation to the corresponding figures of variable $x$ :

$$
x=f\left(I_{s c}, I_{m p}, V_{o c}, V_{m p}\right),
$$

for each photovoltaic device found at the available literature. Based on these points, the following equation is proposed for the Lambert $\mathrm{W}$-function, $W_{-1}$, in the bracket $[-0.364,-0.1]$ :

$$
\begin{aligned}
& W_{-1}(x)= \\
& 248.42 x^{4}+134.24 x^{3}+4.4258 x^{2}-14.629 x-4.9631
\end{aligned}
$$

The above equation has less than $1.6 \%$ error within the mentioned bracket.

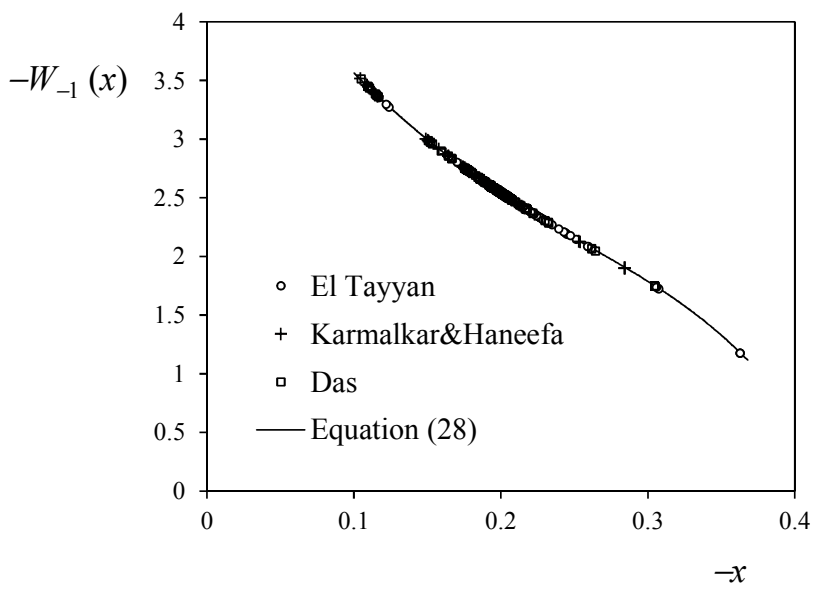

Fig. 7 Lambert W-function, $W_{-1}$ from equations (14), (17), and (20) calculated for the cells/solar panels' data found in the available literature. The approximated equation (28) is also plotted in the graph.

\section{CONCLUSIONS}

The Lambert $\mathrm{W}$-function has revealed as a quite relevant tool for solving the implicit equations that arise when analyzing photovoltaic systems performance. However, working with this mathematical function can be a challenge as it is not represented by any direct equation. In the present work, three simple equations are derived for the Lambert Wfunction in the following cases:

- Calculation of the photovoltaic output current, $I$, as a function of the output voltage, $V$, by using the 1Diode/2-Resistor equivalent circuit model (with all the five parameter well defined).

- Calculation of the series resistor parameter, $R_{s}$, from the 1-Diode/2-Resistor equivalent circuit model in relation to the characteristic points of the $I-V$ curve $\left(I_{s c}, I_{m p}, V_{o c}\right.$, and $\left.V_{m p}\right)$, the ideality factor, $a$, the number of the series-connected cells of the photovoltaic device, and the thermal voltage, $V_{T}$.

- Calculation of the parameters of the explicit methods by El Tayyan, Karmalkar \& Hannefa, and Das.

\section{REFERENCES}

[1] J. Cubas, S. Pindado, and M. Victoria, "On the analytical approach for modeling photovoltaic systems behavior," J. Power Sources, vol. 247, pp. 467-474, Feb. 2014.

[2] J. Cubas, S. Pindado, and C. de Manuel, "Explicit Expressions for Solar Panel Equivalent Circuit Parameters Based on Analytical Formulation and the Lambert W-Function," Energies, vol. 7, no. 7, pp. 4098-4115, Jun. 2014.

[3] J. Cubas, S. Pindado, and A. Farrahi, "New method for analytical photovoltaic parameter extraction," 2nd International Conference on Renewable Energy Research and Applications (ICRERA), Madrid, pp. 873-877, 2013.

[4] J. Cubas, S. Pindado, and C. De Manuel, "New Method for Analytical Photovoltaic Parameters Identification: Meeting Manufacturer's Datasheet for Different Ambient Conditions," Springer Proceedings in Physics 155, vol. 155, pp. 161-169, 2014.

[5] J. Cubas, S. Pindado, and Á. Sanz-Andrés, “Accurate simulation of MPPT methods performance when applied to commercial photovoltaic panels," Sci. World J., vol. 2015, pp. 1-16, 2015.

[6] S. Pindado, J. Cubas, and F. Sorribes-Palmer, "On the Analytical Approach to Present Engineering Problems: Photovoltaic Systems Behavior, Wind Speed Sensors Performance, and High-Speed Train Pressure Wave Effects in Tunnels," Math. Probl. Eng., vol. 2015, pp. 1-17, 2015.

[7] S. Pindado and J. Cubas, "Simple mathematical approach to solar cell/panel behavior based on datasheet information," Renew. Energy, vol. 103, pp. 729-738, 2017.

[8] E. Roibás-Millán, A. Alonso-Moragón, A. Jiménez-Mateos, and S. Pindado, "Testing solar panels for small-size satellites: the UPMSAT2 mission," Meas. Sci. Technol., vol. 28, no. 11, pp. 1-12, 2017.

[9] J. Cubas, S. Pindado, and F. Sorribes-Palmer, "Analytical calculation of photovoltaic systems maximum power point (MPP) based on the operation point," Appl. Sci., vol. 7, no. 9, pp. 1-15, 2017.

[10] S. Pindado, J. Cubas, E. Roibás-Millán, and F. Sorribes-Palmer, "Project-based learning applied to spacecraft power systems: a longterm engineering and educational program at UPM University," CEAS Sp. J., vol. 10, no. 3, pp. 307-323, 2018.

[11] M. Swartwout, "Reliving 24 Years in the Next 12 Minutes: A Statistical and Personal History of University-Class Satellites," 32nd AIAA/USU Conference on Small Satellites, 2018, pp. 1-20.

[12] S. Pindado et al., "Master in Space Systems, an Advanced Master' s Degree in Space Engineering," ATINER'S Conference Paper Series, No: ENGEDU2016-1953, pp. 1-16, 2016.

[13] D. T. Cotfas, P. A. Cotfas, and S. Kaplanis, "Methods to determine the dc parameters of solar cells: A critical review," Renew. Sustain. Energy Rev., vol. 28, pp. 588-596, 2013.

[14] A. K. Tossa, Y. M. Soro, Y. Azoumah, and D. Yamegueu, "A new approach to estimate the performance and energy productivity of photovoltaic modules in real operating conditions," Sol. Energy, vol. 110, pp. 543-560, 2014.

[15] A. Ortiz-Conde, F. J. García-Sánchez, J. Muci, and A. SucreGonzález, "A Review of Diode and Solar Cell Equivalent Circuit Model Lumped Parameter Extraction," FACTA Univ. Ser. Electron. Energ., vol. 27, no. March, pp. 57-102, 2014.

[16] D. Jena and V. V. Ramana, "Modeling of photovoltaic system for uniform and non-uniform irradiance: A critical review," Renew. Sustain. Energy Rev., vol. 52, pp. 400-417, 2015.

[17] V. J. Chin, Z. Salam, and K. Ishaque, "Cell modelling and model parameters estimation techniques for photovoltaic simulator application: A review," Appl. Energy, vol. 154, pp. 500-519, 2015.

[18] A. M. Humada, M. Hojabri, S. Mekhilef, and H. M. Hamada, "Solar cell parameters extraction based on single and double-diode models: A review," Renew. Sustain. Energy Rev., vol. 56, pp. 494-509, 2016.

[19] H. Ibrahim and N. Anani, "Evaluation of Analytical Methods for Parameter Extraction of PV modules," Energy Procedia, vol. 134, pp. 69-78, 2017. 
[20] M. G. Villalva, J. R. Gazoli, and E. R. Filho, "Modeling and circuitbased simulation of photovoltaic arrays," in 2009 Brazilian Power Electronics Conference, Bonito-Mato Grosso do Sul, Brazil, pp. $1244-1254,2009$.

[21] M. G. Villalva, J. R. Gazoli, and E. R. Filho, "Comprehensive Approach to Modeling and Simulation of Photovoltaic Arrays," IEEE Trans. Power Electron., vol. 24, no. 5, pp. 1198-1208, May 2009.

[22] L. Peng, Y. Sun, Z. Meng, Y. Wang, and Y. Xu, "A new method for determining the characteristics of solar cells," J. Power Sources, vol. 227, pp. 131-136, Apr. 2013.

[23] S. Pindado, J. Cubas, E. Roibás-Millán, F. Bugallo-Siegel, and F. Sorribes-Palmer, "Assessment of explicit models for different photovoltaic technologies," Energies, vol. 11, no. 6, pp. 1-22, 2018.
[24] M. Oulcaid, H. El Fadil, L. Ammeh, A. Yahya, and F. Giri, "One shape parameter-based explicit model for photovoltaic cell and panel," Sustain. Energy, Grids Networks, vol. 21, pp. 1-11, 2020.

[25] D. A. Barry, J. Y. Parlange, L. Li, H. Prommer, C. J. Cunningham, and F. Stagnitti, "Analytical approximations for real values of the Lambert W-function," Math. Comput. Simul., vol. 53, no. 1-2, pp. 95-103, 2000. 